\title{
POTENCIAL DO SEBO BOVINO RONDONIENSE COMO MATÉRIA PRIMA PARA PRODUÇÃO DE BIODIESEL EM ARIQUEMES - RO
}

\author{
Naila Fernanda Sbsczk Pereira Meneguetti ${ }^{1}$, Renato André Zan ${ }^{2}$, \\ Dionatas Ulises de Oliveira Meneguetti ${ }^{3}$ \\ ${ }^{1}$ Graduada em Sistemas de Informação, Especialista em Didática e Metodologia do Ensino Superior, Mestranda em \\ Administração pela Universidade Federal de Rondônia (UNIR). \\ ${ }^{2}$ Graduado em Química, Mestre em Química pela Universidade Federal de Santa Maria (UFSM), Docente e \\ Coordenador de Pesquisa e Iniciação Científica da Faculdade de Educação e Meio Ambiente (FAEMA). \\ ${ }^{3}$ Graduado em Biologia, Mestre em Genética e Toxicologia Aplicada pela Universidade Luterana do Brasil (ULBRA), \\ Docente e Coordenador de Extensão da (FAEMA). dionatas@icbusp.org - Avenida Machadinho, 4349, Setor 06, CEP: \\ 76870-293- Ariquemes - Rondônia.
}

http://dx.doi.org/10.5902/223611707636

\section{RESUMO}

O biodiesel é um combustível alternativo, que é produzido pela reação química entre um óleo de origem vegetal ou animal e álcool (metílico ou etílico), reação essa chamada de transesterificação. O presente estudo objetivou um estudo de mercado do potencial do sebo bovino rondoniense como matéria prima para produção de biodiesel em Ariquemes - RO. A pesquisa foi realizada de forma direta, através de visitas aos frigoríficos, rondonienses. Através dos dados obtidos foi realizada uma análise quantitativa, comparando a capacidade de produção da empresa De Paula Biodiesel com a quantidade de produção de sebo das empresas pesquisadas. $O$ estudo levou em conta a produção diária e mensal de gordura animal produzida por abatedouros e frigoríficos avaliando o número de abates dia efetuados pelos mesmos e que para cada animal abatido se obtém em média $10 \mathrm{Kg}$ de sebo, foi onde se chegou ao número de $133.327 \mathrm{Kg}$ de sebo dia, levando em consideração que cada kg de sebo produz 0,95 litros de biodiesel, a matéria prima é suficiente para produzir 126.660 litros, mais que o dobro da produção diária, mostrando o grande potencial de matéria prima disponíveis nos frigoríficos. Contatou se que o potencial do sebo bovino rondoniense como matéria prima para produção de biodiesel, é satisfatório, suprindo mais do que o dobro da produção máxima da empresa, sendo os frigoríficos Minerva e Cooperativa Construção, os maiores produtores de sebo, tendo como a principal cidade o município de Ariquemes - RO.

Palavras - Chave: Potencial, Sebo Bovino e Biodiesel.

\section{ABSTRACT}

The biodiesel is an alternative oil, that's produced by the reaction chemical between an originally vegetable or animal and alcohol (methyl or ethyl), reaction called of transesterification. The present study have the objective of looking for potential of bovine fat Rondoniense in the fair regard raw material of production biodiesel. The survey was held of direct form, through visits at Rondoniense cold stores. Through of information's realized throughout quantitative analysis, comparing capacity of production of company De Paula Biodiesel with amount the production of fat companies surveyed. The study led in consideration the daily and monthly production, the animal fat produced slaughterhouse and cold stores evaluating a number of slaughter daily accomplished, and for each animal dead get in media $10 \mathrm{~kg}$ of fat, where they got the number of $133.327 \mathrm{Kg}$ of fat daily, leading in consideration that for each $\mathrm{Kg}$ of fat it is produced $0,95 \mathrm{lt}$ of 
Rev. Elet. em Gestão, Educação e Tecnologia Ambiental (e-ISSN: 2236-1170)

biodiesel. The raw material is enough to produce $123.660 \mathrm{lt}$, more than double of daily production, showing a big potential raw material available on the cold stores. Has been found the potential of bovine fat Rondoniense like raw material for production of the biodiesel, were satisfactory supplying more than the double of production maxima of the company, being the cold stores Minerva e Cooperativa Construção, the biggest producers of fat, having as a principal city Ariquemes - RO.

Key - Words: Potential, Bovine Fat and Biodiesel.

\section{INTRODUÇÃO}

A maior parte de toda a energia consumida no mundo provém do petróleo, uma fonte limitada, finita e não renovável (SANTOS; PINTO, 2009). Entre todos os derivados do petróleo o mais consumido no Brasil é o óleo diesel e mesmo assim sendo autossuficiente em petróleo bruto não tem o número de refinarias necessárias para refinar o petróleo e suprir a necessidade nacional (OLIVEIRA; PONTES, 2011), sendo uma fração crescente desse produto importado anualmente (NOGUEIRA; PIKMAN, 2012; MENEGUETTI et al., 2011). Assim, é necessária a importação do diesel que está cada vez mais caro. Além disso, o diesel é um grande emissor de enxofre, o que causa sérios danos ao meio ambiente (RINALDI et al., 2007; LOBO et al., 2009). Portanto, a busca por fontes de energia alternativas de energia é de grande importância para a economia brasileira (GUARIEIRO, 2006; SANTOS; PINTO, 2009), como solução a todos esses problemas surge o biodiesel que possui as mesmas características físico-químicas do diesel do petróleo (OLIVEIRA; PONTES, 2011).

Sua história iniciou-se no ano de 1900, quando o próprio Rudolph Diesel apresentou um protótipo de motor na Exposição Universal de Paris, que foi acionado com óleo de amendoim, cultura que era muito difundida nas colônias francesas na África. No entanto, a abundância da oferta de petróleo e o seu preço acessível determinaram que, nos anos seguintes, os derivados do petróleo fossem os combustíveis preferidos, reservando os óleos vegetais para outros usos, além dos óleos vegetais apresentarem dificuldades para se obter uma boa combustão, atribuídas à sua elevada viscosidade, o que impedia uma adequada injeção nos motores, acumulando carbono nos cilindros e nos injetores, sendo necessária uma manutenção intensiva dos mesmos (GONÇALVES; NOGUEIRA, 2007).

Mesmo com esses problemas na década de 30, o governo francês incentivava as experiências com o óleo de amendoim visando conquistar a independência energética. Porém, o desenvolvimento dos combustíveis de origem vegetal foi praticamente abandonado quando o fornecimento de petróleo foi restabelecido (KNOTHE, 2001).

A pesquisa realizada para resolver os problemas de viscosidade, conduziu à descoberta da transesterificação, este tratamento permitiu superar as dificuldades com a combustão. Os primeiros a utilizar a feliz denominação de biodiesel para os combustíveis foram os pesquisadores chineses, em 1988 (KNOTHE et al., 2006).

Hoje o biodiesel é definido como um combustível alternativo para motores a diesel, esse que é produzido pela reação química entre um óleo de origem vegetal ou animal e álcool (metílico ou etílico), reação essa chamada de transesterificação. (GUIDOLIN et al., 2006).

O biodiesel é considerado uma das principais soluções para suprir o esgotamento das fontes de energia fósseis que está prevista para os próximos 40 ou 50 anos, destacando a necessidade latente de se buscar outras fontes alternativas. Somado a isso, os constantes conflitos 
Rev. Elet. em Gestão, Educação e Tecnologia Ambiental (e-ISSN: 2236-1170)

políticos, envolvendo os países do Oriente Médio, onde estão localizadas quase $80 \%$ das reservas comprovadas de petróleo no mundo, conferem instabilidade ao suprimento e aos preços do combustível, incentivando várias nações a reduzirem a dependência em relação às importações do produto. Assim, energia e tecnologia são dois fatores importantes para o desenvolvimento econômico. Graças a eles será possível sustentar uma população mundial de 9 bilhões prevista pela ONU para 2070 (CASTELLANELLI, 2008).

A demanda brasileira por biodiesel tende a aumentar consideravelmente devido aos seguintes fatores: necessidade de redução da dependência de derivados de petróleo nas matrizes energéticas nacionais; incentivo à agricultura e às indústrias locais; desenvolvimento de estratégias para a redução e/ou limitação do volume de emissões de gases causadores do efeito estufa até o presente ano de 2012, conforme acordado pelo Protocolo de Quioto (SAUER et al., 2006), essa redução quando comparada ao óleo diesel pode atingir $98 \%$ de redução de enxofre, $30 \%$ de aromáticos e $50 \%$ de material particulado e no mínimo $78 \%$ de gases do efeito estufa (ROSA et al., 2003).

Essa adoção do biodiesel mesmo que de forma progressiva no Brasil foi regulamentada pela Lei $11.097 / 2005$ que dispõe sobre a introdução do biodiesel na matriz energética brasileira, que altera as Leis 9.478, de 6 de agosto de 1997; 9.847, de 26 de outubro de 1999; e 30 de dezembro de 2002.

A lei permite a atuação reguladora da Agência Nacional do Petróleo (ANP) sobre o biodiesel. De acordo com a lei, a ANP passa a se chamar Agência Nacional do Petróleo, Gás Natural e Biocombustíveis e passa a ter atuação reguladora também sobre o setor de combustíveis de fontes renováveis. O percentual mínimo obrigatório de adição de biodiesel ao óleo diesel comercializado no país foi fixado em $5 \%$, percentual este a ser alcançado em oito anos, esse prazo que vence em 2013 (BRASIL, 2012).

Graças a essa lei aumentou consideravelmente os incentivos fiscais para a produção de energias renováveis, apresentando o Brasil ótimas condições para se tornar um dos maiores produtores de biodiesel no mundo, não só porque dispõe de solo e clima adequado ao cultivo de várias oleaginosas, mas também porque possui o segundo maior rebanho bovino, em números de cabeças (177,7 milhões) e a primeira como rebanho comercial no mundo (ANUALPEC, 2010). A gordura animal ou sebo é uma excelente matéria prima já que seu aproveitamento é praticamente total. O Brasil produz hoje, aproximadamente, 900.000 toneladas ao ano de sebo, havendo assim um grande potencial para a produção de óleo utilizando essa matéria prima (SAUER et al., 2006), que na produção brasileira de biodiesel responde por cerca de $17 \%$ do total produzido (MARTINS et al., 2011), chegando em dezembro de 2010 a mais de $20 \%$, conforme (Figura - 1 ). 
Rev. Elet. em Gestão, Educação e Tecnologia Ambiental (e-ISSN: 2236-1170)

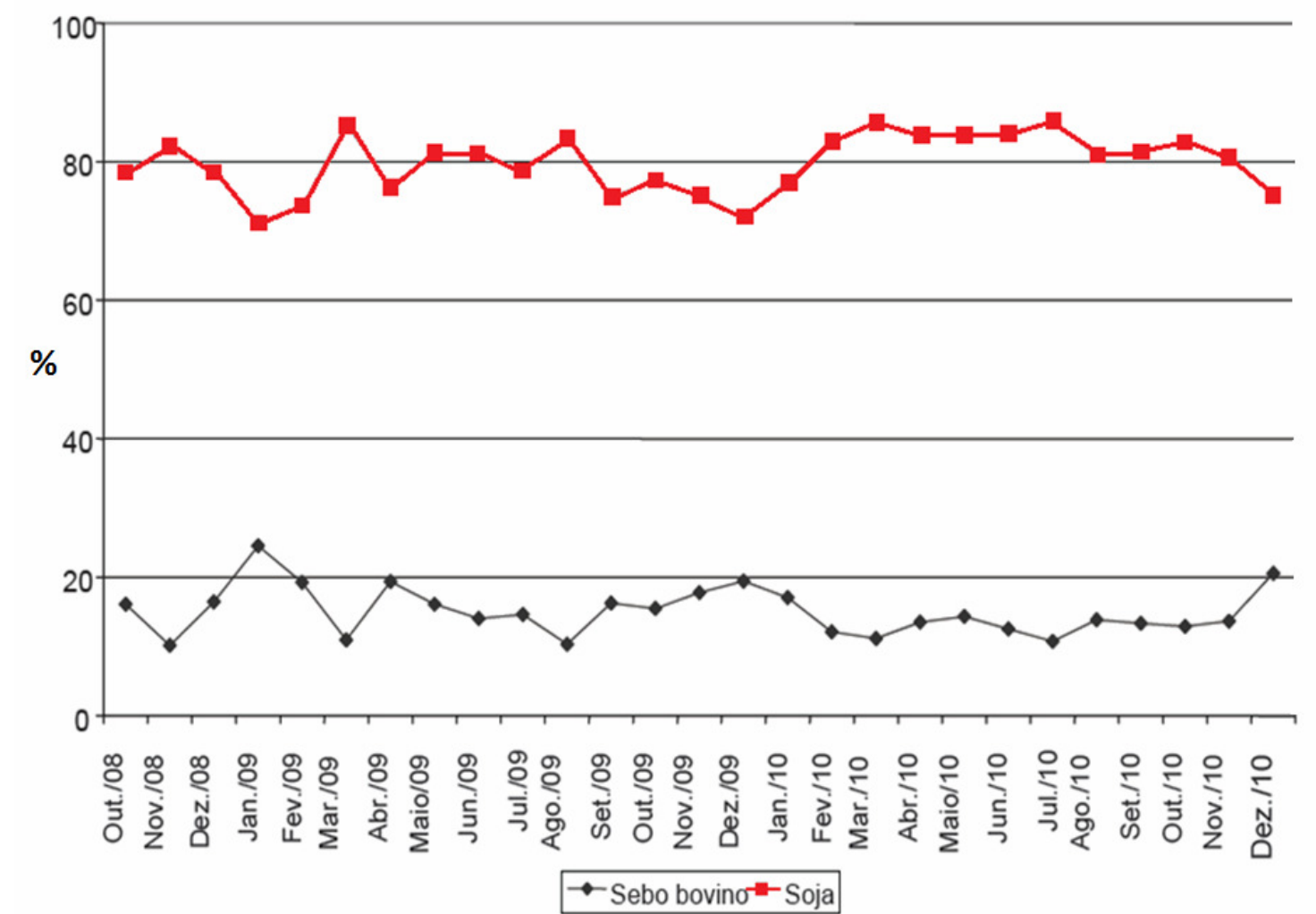

Figura 1 - Participação percentual da soja e do sebo bovino na produção brasileira de biodiesel, outubro de 2008 a dezembro de 2010. Adaptado de (MARTINS et al., 2011).

O preço do sebo bovino, historicamente, tem uma relação direta com a cotação da arroba do boi gordo. Com a participação do sebo na produção de biodiesel, a paridade entre os dois mercados sofreu alterações, principalmente nos anos de 2007 e 2008, quando o sebo bovino passa a ocupar espaço na produção de biodiesel. Nesse período, o valor do sebo salta de $R \$ 774,00$ a tonelada, preço médio de 2006 , para $\mathrm{R} \$ 1.870,00$ por tonelada, a cotação média para 2008; nos dois anos seguintes é possível verificar a acomodação nos preços do sebo e uma relação mais próxima ao comportamento do preço da arroba do boi gordo (MARTINS et al., 2011) (Figura - 2). 
Rev. Elet. em Gestão, Educação e Tecnologia Ambiental (e-ISSN: 2236-1170)

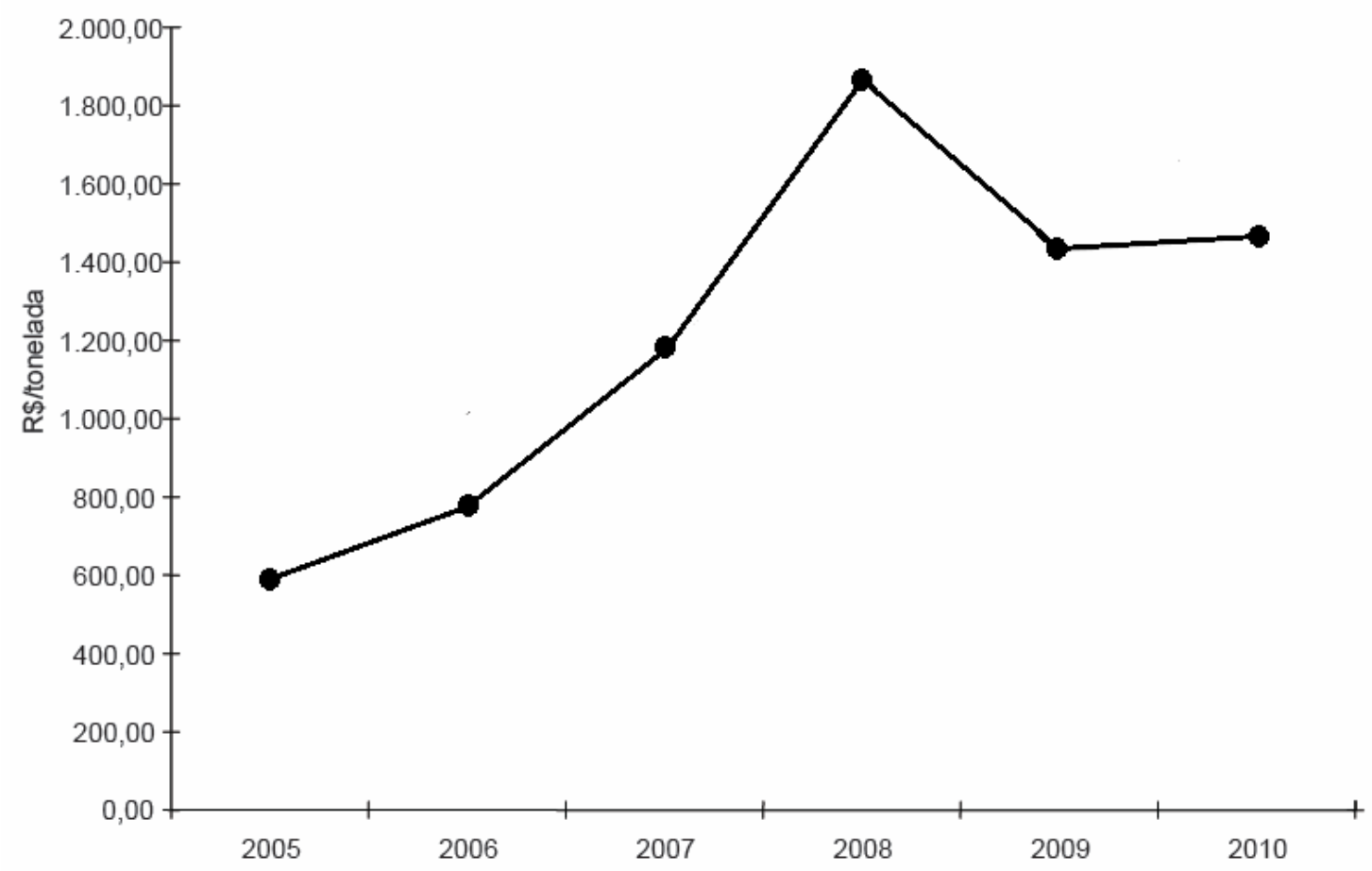

Figura 2. Evolução do preço de sebo bovino, média anual em valores nominais, Brasil, 2005 a 2010 (IEA, 2012).

Com toda essa evolução a empresa em estudo, antes mesmo do início de operação de sua unidade, já está preocupada com as fontes de fornecimento de sua matéria prima, nesse sentido vem buscando junto aos frigoríficos da região parcerias no fornecimento de sebo bovino. 0 presente estudo objetivou realizar um estudo de mercado do potencial do sebo bovino rondoniense como matéria prima para produção de biodiesel em Ariquemes - RO.

\section{MATERIAIS E MÉTODOS}

\section{A Empresa}

A empresa De Paula Biodiesel está situada na Via Principal, S/№, GL.01, Chácara 07, St.60, CEP 78.930-000, zona rural do município de Ariquemes, Rondônia.

A De Paula Biodiesel contará com uma plataforma de recebimento de matéria prima e carregamento de produto acabado que será equipada com bombas de vazão de $41,5 \mathrm{~m}^{3} / \mathrm{h}$ tanto no recebimento da matéria prima como no produto final.

Sua capacidade de produção diária, mensal e anual para as duas rotas reacionais (Etílica e Metílica) está descrita na (Tabela -1). 
Rev. Elet. em Gestão, Educação e Tecnologia Ambiental (e-ISSN: 2236-1170)

Tabela 1. Capacidade de produção diária, mensal e anual para as duas rotas reacionais (Etílica e Metílica) da empresa De Paula Biodiesel.

\begin{tabular}{cll}
\hline \multicolumn{1}{c}{ Rota Etílica } & \multicolumn{1}{c}{ Rota Metílica } \\
\hline Diária & 42,5 mil litros de biodiesel & 50 mil litros de biodiesel \\
& 4,2 ton. Glicerina & 5 ton glicerina \\
\hline \multirow{2}{*}{ Mensal } & 1,01 milhões de litros de Biodiesel & 1,22 milhões de litros de Biodiesel \\
& 100,8 ton. glicerina & 120 ton. glicerina \\
\hline \multirow{2}{*}{ Anual } & 12,2 milhões de litros de Biodiesel & 14,4 milhões de litros de Biodiesel \\
& 1,21 mil ton. glicerina & 1,44 mil ton. glicerina
\end{tabular}

No Brasil, em termos econômicos, a vantagem da rota etílica em relação à metílica para a produção de biodiesel é a oferta do álcool etílico em todo território nacional, possibilitando com isso custos diferenciados de fretes para o abastecimento do etanol. Também com etanol têm-se um combustível ecológico correto, com ambas as fontes - álcool e óleo - sendo renováveis. Apesar disso, a produção de biodiesel com metanol é mais rápida (ocorre à separação da glicerina dos ésteres com maior facilidade) e com menor custo operacional. A utilização do metanol no processo de transesterificação reduz à metade o custo quando comparado ao processo com etanol (KRAUSE, 2008).

\section{Estudo de Mercado do potencial do sebo bovino rondoniense}

A pesquisa foi realizada de forma direta, através de visitas aos frigoríficos, Friboi em Vilhena e Porto Velho; Friboi e Coopero Carne em Pimenta Bueno; Friboi I, Friboi II, Frigocal e Frigoserve em Cacoal; Marfring em Chupinguaia; Margem, Independência, Serra Azul e Minerva em Rolim de Moura; Guaporé Carnes S/A em São Miguel do Guaporé; Tangará, Rondosafra e Frialto em Ji-paraná; Frigon em Jaru; Santa Marina, Margen, Cooperativa Construção e Amorim em Ariquemes; Abatedouro em Candeias do Jamari; além de outros 28 pequenos abatedouros na região do Vale do Jamari (Figura 3). 


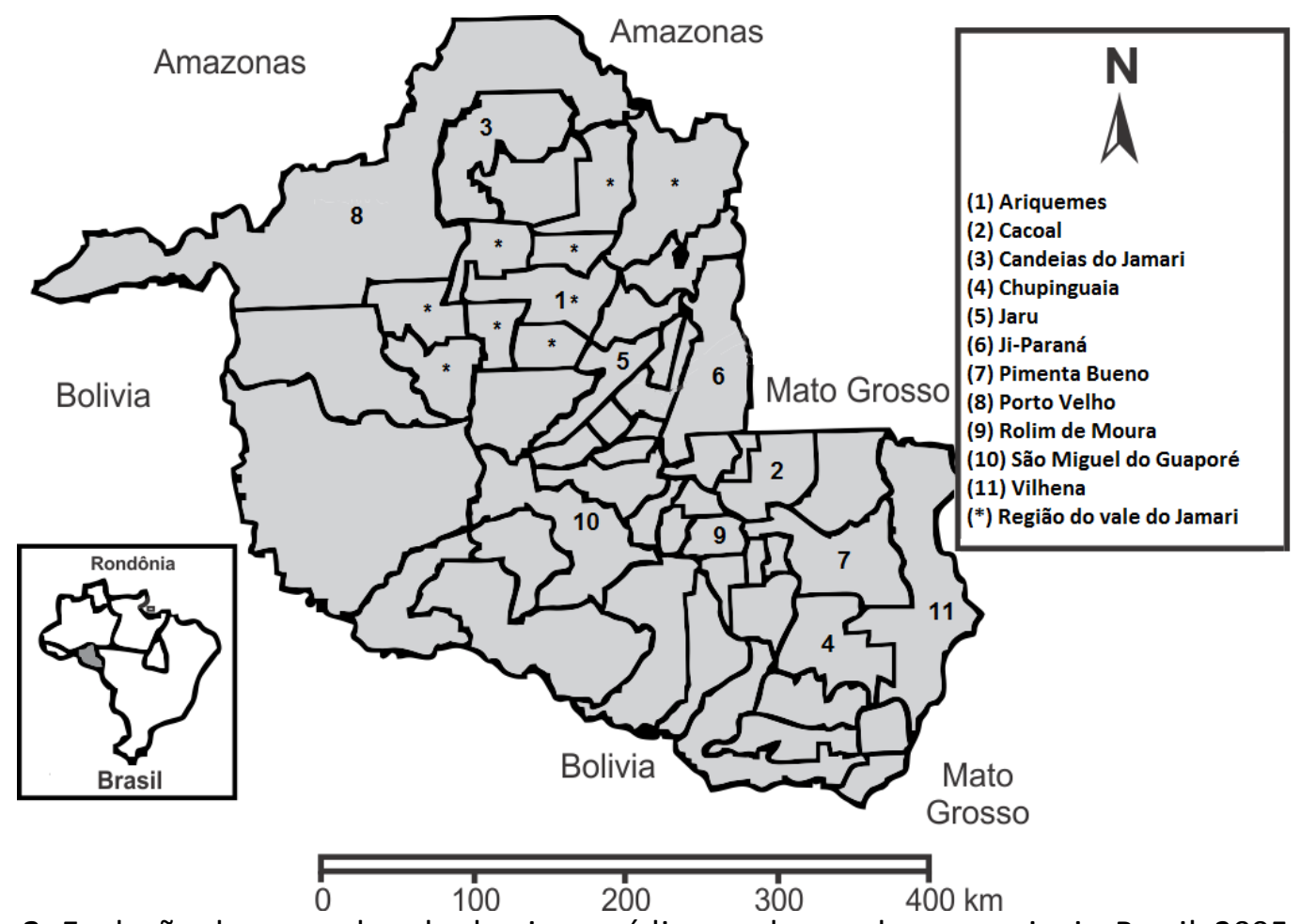

Figura 3. Evolução do preço de sebo bovino, média anual em valores nominais, Brasil, 2005 a 2010 (IEA, 2012).

Através dos dados obtidos foi realizada uma análise quantitativa, comparando a capacidade de produção da empresa De Paula Biodiesel com a quantidade de produção de sebo, das empresas pesquisadas.

\section{RESULTADOS E DISCUSSÕES}

Os frigoríficos pesquisados, sua localização, número de cabeças abatidas ao dia e sua produção de sebo diária, estão representadas na (Tabela - 2).

Tabela 2. Frigoríficos pesquisados, sua localização, número de cabeças abatidas ao dia e sua produção de sebo diária.

\begin{tabular}{cccc}
\hline Potencial Fornecedor & Localização & $\begin{array}{c}\text { No Cabeças } \\
\text { Abate/dia }\end{array}$ & $\begin{array}{c}\text { Produção de sebo } \\
(\mathbf{1 0 K g / c a b e c ̧ a ~ a b a t i d a ) ~}\end{array}$ \\
\hline Friboi & Vilhena & 850 & 8.500 \\
\hline Friboi & Pimenta Bueno & 300 & 3.000 \\
\hline Friboi & Porto Velho & 300 & 3.000 \\
\hline Friboi I & Cacoal & 400 & 4.000 \\
\hline Friboi II & Cacoal & 300 & 3.000 \\
\hline Marfrig & Chupinguaia & 430 & 4.300 \\
\hline Coopero Carne & Pimenta Bueno & 600 & 6.000 \\
\hline Frigocal & Cacoal & 150 & 1.500 \\
\hline
\end{tabular}


Rev. Elet. em Gestão, Educação e Tecnologia Ambiental (e-ISSN: 2236-1170)

\begin{tabular}{cccc}
\hline Frigoserve & Cacoal & 50 & 500 \\
\hline Margem & Rolim de Moura & 600 & 6.000 \\
\hline Independência & Rolim de Moura & 500 & 5.000 \\
\hline Serra Azul & Rolim de Moura & 50 & 500 \\
\hline Minerva & Rolim de Moura & 1500 & 15.000 \\
\hline Guaporé Carnes S/A & São Miguel do Guaporé & 200 & 2.000 \\
\hline Tangará & Ji-Paraná & 800 & 8.000 \\
\hline Rondosafra & Ji-Paraná & 3.000 \\
\hline Frialto & Ji-Paraná & 12.500 \\
\hline Frigon & Jaru & 13.000 \\
\hline Santa Marina & Ariquemes & 8.000 \\
\hline Margen & Ariquemes & 6.000 \\
\hline Cooperativa (construção) & Ariquemes & 1300 \\
\hline Amorim & Ariquemes & 800 & 15.000 \\
\hline Abatedouro & Candeias do Jamari & 3.000 \\
\hline unidades) & Região do vale do Jamari & 1.000 \\
\hline & & 300 & 2.670
\end{tabular}

Os frigoríficos com maior produção de sebo são: Cooperativa (construção), Minerva, Frigon e Frialto, conforme pode ser observado na (Figura -4).

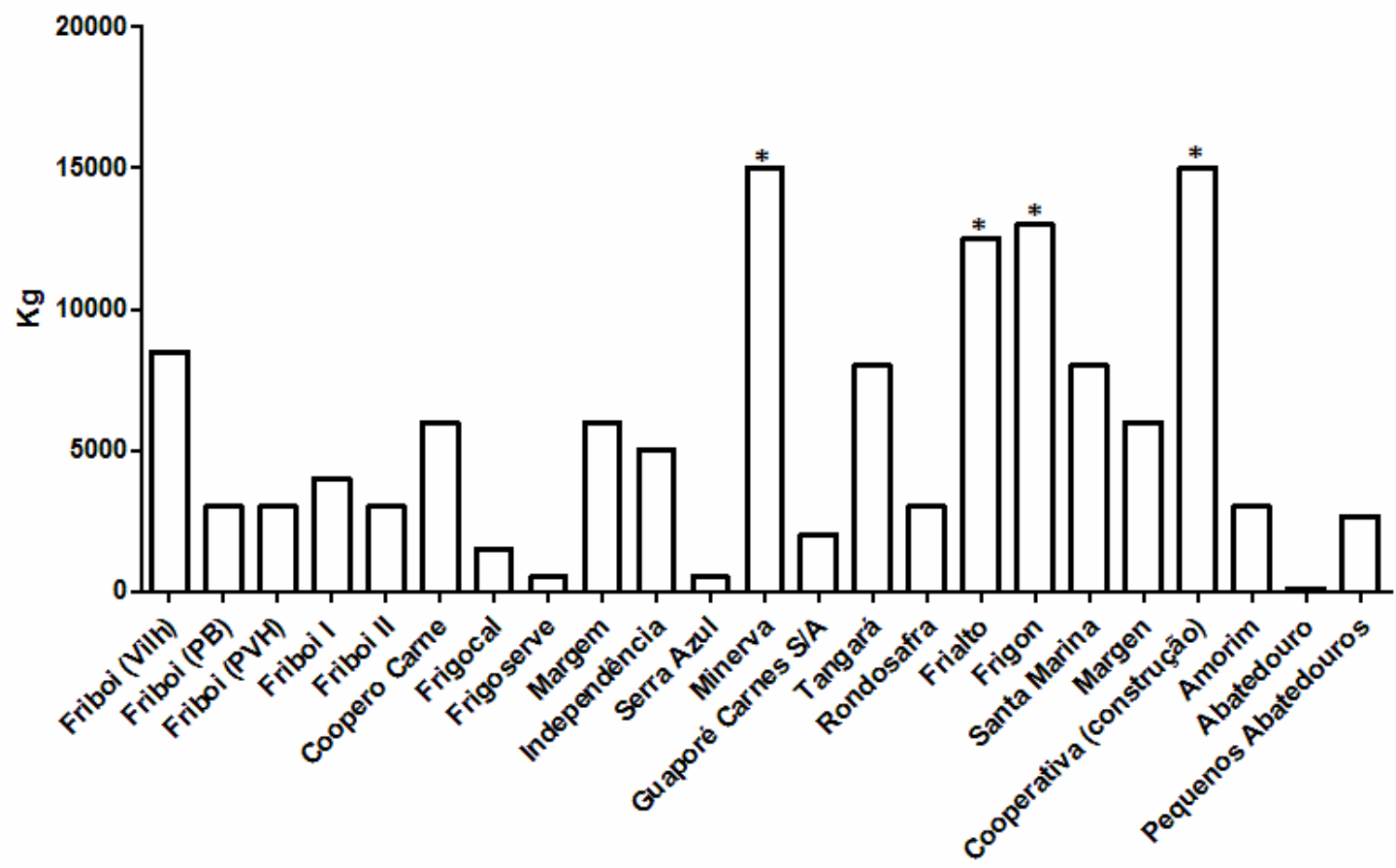

Figura 4 - Produção diária de sebo dos frigoríficos estudados (* frigoríficos com maior produção).

As cidades com maior produção de sebo são: Ariquemes, Ji-paraná e Rolim de Moura conforme pode ser observado na (Figura -5). 


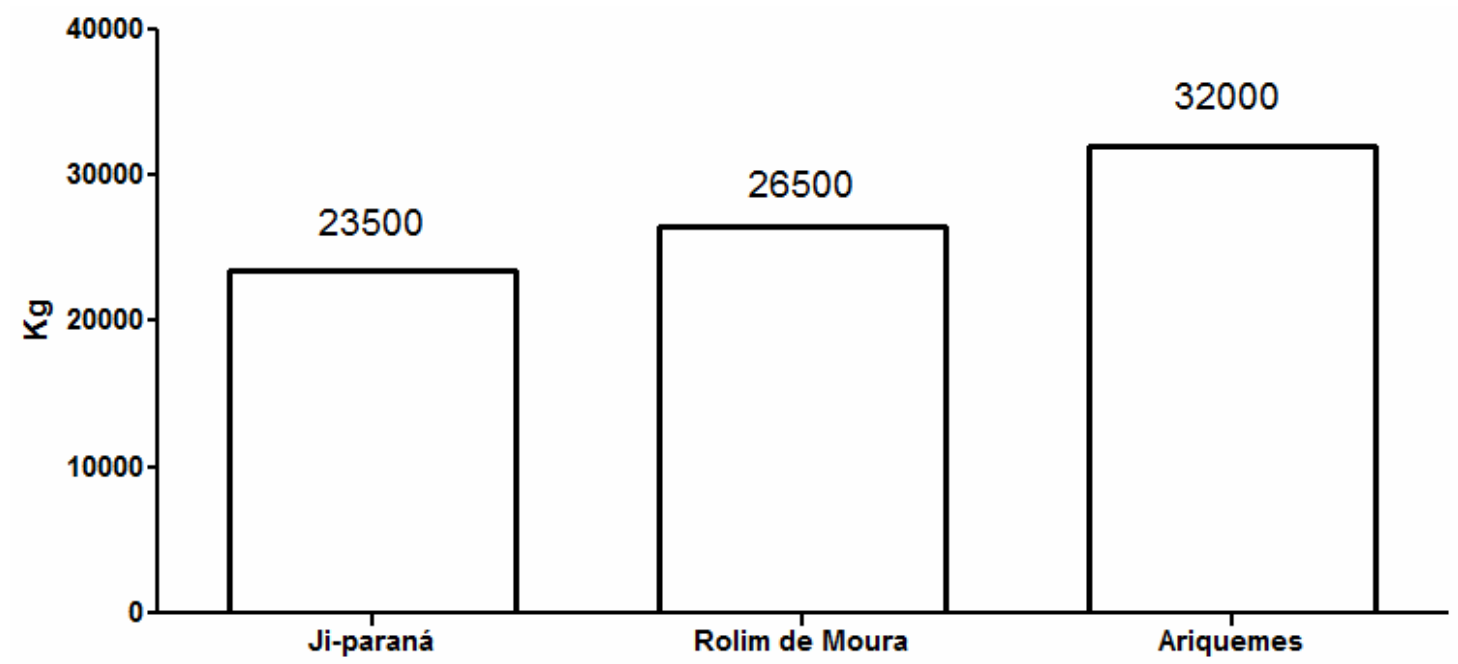

Figura 5 - Produção de sebo diária das cidades estudadas com maior produção.

O estudo levou em conta a produção diária e mensal de gordura animal produzida por abatedouros e frigoríficos avaliando o número de abates dia efetuados pelos mesmos e que para cada animal abatido se obtém um mínimo $10 \mathrm{Kg}$ de sebo, foi onde se chegou ao número de 133.327 Kg de sebo dia, levando em consideração que cada kg de sebo produz 0,95 litros de biodiesel, a matéria prima é suficiente para produzir 126.660 litros, mais que o dobro da produção diária da empresa, mostrando o grande potencial de matéria prima disponíveis nos frigoríficos. Esses números podem ser ainda maiores, pois de acordo com o Boletim Mensal dos Combustíveis Renováveis de fevereiro de 2011, esses índices podem chegar a uma média de $15 \mathrm{Kg}$ de sebo por animal (BRASIL, 2011).

Também foi realizada uma avaliação do mercado consumidor da região do Vale do Jamari, nesse estudo realizou se um levantamento médio do consumo de diesel na região e o interesse de algumas empresas com frota cativa de veículos a diesel em estar utilizando o biodiesel produzido como combustível ao invés da diesel convencional, conforme pode ser observado na (Tabela -3).

Tabela 3. Mercado consumidor de biodiesel da região do Vale do Jamari.

\begin{tabular}{|c|c|c|}
\hline Tipo de empresa consumidora & Quantidade & Volume de óleo Mês \\
\hline Prefeituras & 22 & 220.000 \\
\hline Cooperativas & 08 & 80.000 \\
\hline Empresas de ônibus & 06 & 100.000 \\
\hline Empresas de construtoras e empreiteiras & 10 & 30.000 \\
\hline Total & 46 & 430.000 \\
\hline
\end{tabular}

Se considerarmos o funcionamento da empresa 21 dias ao mês, a mesma produzirá 1.050.000 litros, quase metade dessa produção já teria destino certo, mesmo esse não sendo o principal foco da empresa, que tem como objetivo principal a venda de sua produção nos leilões da ANP. 
Rev. Elet. em Gestão, Educação e Tecnologia Ambiental (e-ISSN: 2236-1170)

\section{CONCLUSÃO}

Contatou se que o potencial do sebo bovino rondoniense como matéria prima para produção de biodiesel pela empresa De Paula Biodiesel, é satisfatório, suprindo mais do que o dobro da produção máxima da empresa, sendo os frigoríficos Minerva e Cooperativa Construção, os maiores produtores de sebo, tendo como a principal cidade o município de Ariquemes - RO.

É importante ressaltar se caso a reação de transesterificaçao seja incompleta ou caso a purificação seja insuficiente, o biodiesel produzido pode ficar contaminado com glicerol livre e retido, triglicerídeos, álcool e resíduos do catalisador, e a presença desses contaminantes pode ser prejudicial para os motores e para o meio ambiente.

Indica-se estudos futuros para analisar o potencial de outras matérias primas, como oleaginosas e óleos de frituras, além de uma análise da viabilidade financeira para a produção do biodiesel a partir dessas matérias primas.

\section{REFERÊNCIAS}

ANUALPEC. Anuário da pecuária brasileira 2010. São Paulo: AgraFNP, 2010, 360 p.

BRASIL. Boletim mensal dos combustíveis renováveis. Ministério de Minas e Energia Secretaria de Petróleo, Gás Natural e Combustíveis Renováveis Departamento de Combustíveis Renováveis, edição n. 38, fevereiro, 2011.

BRASIL. Presidência da República. Lei no 11.097, de 13 de janeiro de 2005. Disponível em: <http://www.planalto.gov.br/ccivil_03/_ato2004-2006/2005/Lei/L11097.htm>. Acesso em 20/05/2012.

CASTELLANELLI, C.A. Estudo da viabilidade de produção do biodiesel, obtido através do óleo de fritura usado, na cidade de Santa Maria, RS. (Dissertação) Mestrado em Engenharia de Produção. Universidade Federal de Santa Maria (UFSM, RS), 2008.

GUARIEIRO, L.L.N. Metodologia analítica para quantificar o teor de biodiesel na mistura biodiesel: diesel utilizando espectrometria na região do infravermelho. Dissertação de Mestrado. Instituto de Química, Programa de Pós Graduação em Química Orgânica, Universidade Federal do Rio de Janeiro. Rio de Janeiro, 2006.

GUIDOLIN, L.R.; SCHWALBERT, M.P.; JAHN, S.L.; FOLETTO, E.L. Produção de biodiesel a partir de sebo bovino. CRICTE, XXI Congresso de Iniciação Científica e Tecnológica em Engenharia, VI Feira de Protótipos. 2006.

INSTITUTO DE ECONOMIA AGRÍCOLA - IEA. Banco de dados: preços agrícolas. São Paulo: IEA, 2011. Disponível em: <http://ciagri.iea.sp.gov.br/bancoiea/precos_medios.aspx? cod_sis=2>. Acesso em 18/05/2012.

KNOTHE, G.; GERPEN, J.V.; KRAHL, J.; RAMOS, L.P. Manual de Biodiesel, São Paulo: Ed. Edgard Blucher, 2006. 
Rev. Elet. em Gestão, Educação e Tecnologia Ambiental (e-ISSN: 2236-1170)

KNOTHE, G. Perspectivas históricas de los combustibles diesel basados em aceites vegetales. Revista A\&G, 47, Tomo XII, No. 2., 2001.

KRAUSE, L.C. Desenvolvimento do processo de produção de Biodiesel de origem animal. (Tese) Doutorado em Química. Universidade Federal do Rio Grande do Sul (UFRGS), 2008.

LOBO, I. P.; FERREIRA, S.L.C.; DA CRUZ, R.S.; Biodiesel: parâmetros de qualidade e métodos analíticos, Química Nova, v. 32, p. 1596-1608, 2009.

MARTINS, R.; NACHILUK, K.; BUENO, C.R.F.; FREITAS, S.M. O biodiesel de sebo bovino no Brasil. Informações Econômicas, São Paulo, v. 41, n.5, maio 2011.

MENEGUETTI, N.F.S.P.; ZAN, R.A.; MENEGUETTI, D.U.O.; Panorama das Culturas temporárias de girassol e mamona no cenário nacional como incentivo a produção da mesma na região amazônica. VIII CONVIBRA ADMINISTRAÇÃO - Congresso Virtual Brasileiro de Administração, 2011.

NOGUEIRA, R.G.; GONÇALVES, M.A.B. O efeito estufa pode ser reduzido com a produção e a utilização do biodiesel? Revista Processos Químicos, p. 51-59, jul./dez. de 2007.

NOGUEIRA, L.A.H.; PIKMAN, B. Biodiesel; novas perspectivas de sustentabilidade. Conjuntura \& Informação - Agência Nacional do Petróleo, n.19, 2002.

OLIVEIRA, J.L.; PONTES, L.F.B.L.; Preparação e digestão de amostras de biodiesel de sebo bovino e óleo residual de fritura. VI Congresso de Iniciação Científica do IFPE - Instituto Federal de Educação, Ciência e Tecnologia de Pernambuco, 2011.

RINALDI, R.; GARCIA, C.; MARCINIUK, L.L.; ROSSI A.V.; SCHUCHARDT, U. Química Nova, v. 30, p. 1374-1380, 2007.

ROSA, L.P. et al. Geração de Energia a partir de Resíduos Sólidos Urbanos e Óleos Vegetais. Fontes Alternativas de Energia no Brasil. CENERGIA. 1a Ed. Editora Interciência. 515 p., 2003.

SANTOS, A.P.B.; PINTO, A.C. Biodiesel: Uma Alternativa de Combustível Limpo. Química Nova na Escola, vol. 31, n. 1, fevereiro de 2009.

SAUER, I.L.; QUEIROZ, M.S.; MIRAGAYA, F.C.G.; MASCARENHAS, R.C.; QUINTINO JÚNIOR, A.R. Energias renováveis: ações e perspectivas na Petrobras. Bahia Análise e Dados, Salvador, v. 16, n. 1, p. 9-22, jun. 2006. 